Original Research Paper

\title{
The Role of Six Sigma Approach by Applying (DMAIC) Model and Forming Work Team in Improving Banks Performance: A Survey Study in Syrian Banks in Damascus
}

\author{
${ }^{1,2}$ Mohamad Abdulrahman Qutait \\ ${ }^{I}$ Department of Banking and Finance, Bilad Al Sham University, Damascus, Syria \\ ${ }^{2}$ Faculty of Economic and Management, Putra University Malaysia, Selangor, Malaysia
}

Article history

Received: 15-03-2018

Revised: $30-05-2018$

Accepted: 09-08-2018

Email: qutait.Mohamad@yahoo.com

\begin{abstract}
Banking systems face many changes and challenges that require the application of new performance management and improvement concepts and an attempt to achieve excellence. Six Sigma is one of the best methodologies that can help in this regard because it can be used to improve the performance of banks and reduce defects in their operations. This study aimed to highlight the role of the Six Sigma approach to improve the performance of Syrian Islamic banks according to the implementation of the six elements of the Sigma model (DMAIC) and the selection of Six Sigma teams (Team Improvement). The results of the study indicate the importance of implementing Six Sigma methodology in all local sections including industrial and service organizations and there is a trend in Syrian banks to take advantage of the Six Sigma approach. The results also show that there is a statistically significant effect application of six sigma model elements (DMAIC), Selecting six sigma team (Improvement Team) and the performance improvement of Syrian banks. Based on that, several recommendations were presented. Among these recommendations were the urgency and the need of benefiting from the best practices in the field of Six Sigma. Invest in training and provide the employees with some experience in this field.
\end{abstract}

Keywords: Six Sigma (DMAIC) Model, Work Team, Performance Improvement

\section{Introduction}

The banking sector is the most vital instrument in the field of services. The banking industry is the main driver of economic growth. It helps to manage the economic, financial and commercial processes, implement the state's financial policies and apply its monetary system. The complexity of the surrounding environment and the constant changes in it constantly, business performance has become required to adopt new management practices that support the success of business consistently and achieve outstanding performance.

Recent Management Methodologies at the Level of Global Organizations Include Six Sigma (Six Sigma)

It represents one of the most important administrative concepts in the world of business administration, which can be applied to the various administrative procedures in banks. It represents a management methodology and philosophy based on a firm building that seeks to focus the effort to obtain services that are very close to the highest quality, In a record time, it relies on the growing analysis of data and accumulated statistics to identify the defects and defects in the procedures, so as to work on them permanently and try to reduce the percentage of errors to reach zero defect whenever possible, specifically 3.4 defects per million chances.

The issue of raising performance is one of the main topics that receive wide attention from business organizations.

The company has recently moved to support the processes of improvement and development to provide the best and to have the elements of continuous success.

Policies in the industrial sector, organizational structures and business structures should therefore be built on the basis of continuous improvements in their operations and 
activities through a number of methodologies and methods to achieve the best performance. The most important of these are six approaches (6) which adopt the principle of continuous improvement of all FAO operations (DMAIC) based on the following steps: (Identification, Measurement, Analysis, Optimization, R and B), by applying statistical tools and tools Helical.

This research provides a six-syllabus methodology in Syrian marshes to try to reduce errors in their operations, improve the quality of their outputs and keep up with the realities of the new business environment.

\section{Research Problem}

The industrialization industry is characterized by rapid change due to many factors such as globalization, reorganization and technological innovations, which forced commercial, savings and specialized industrial, agricultural and real estate estates in the national economy to rethink their strategies especially in light of the development of national and international policies, Thus, the pursuit of continuity, the level of competitiveness and the growth in market share requires responding to the rapid changes that affect the work environment and contain the pressures that it faces. In this dynamic environment. The activation of the Syrian infrastructure.

In an integrated manner in the last period of the emergence of traditional and Islamic marshes and private banking entities to form the optimal composition in the financial markets 1 to the economic arena, it is imperative to take advantage of the reforms that support the banking entities and the development of performance.

And from the modernity of the six methodologies will be a sophisticated method to improve performance and requires the Syrian banks to work on continuous innovation so that the mistakes are overcome and increase efficiency and meet the needs of customers trying to get defects to the lowest level. The SIX SIGMA standard achieves $99,997 \%$ of the total achievement of the SIX SIGMA. In other words, the error is 3.4 million, thus achieving the best level in all the work done. Out.

Therefore, the problem of research is to answer the following communications:

- Is the basic strategy to focus on using the Six Sigma methodology within Syrian banking systems?

- To what extent is the adoption of the Six Sigma program in the Syrian banks under study?

\section{Research Assumes}

The first hypothesis: The implementation of the Six Sigma (DMAIC) elements in the performance of the Syrian banks does not affect the performance of the banks.

The second hypothesis: The selection of the Six Sigma teams does not affect the performance of Syrian banks.

\section{The Importance of the Research and its Objectives}

The importance of the research is that the methodology of six of the topics of modern management science, especially in the field of banks that take the lead in the services sector and the scarcity of research available in this regard and thus can be considered as an attempt to demonstrate how to achieve improved performance and improve banking to excellence In the results of the banking business, through the knowledge of the role of the Six Sigma development program in the banking sector, which consists of the formation of teams of specialists trained in how to identify problems and then find solutions and implement solutions to enhance improvements in the performance of banking institution During the execution of the business, the objectives of the research are:

1) Highlighting one of the modern administrative concepts in administrative thought, which is a six Sigma approach and an indication of its importance

2) Try to highlight the reasons for the interest of banking organizations using six Sigma

3) Supporting the Syrian commercial and savings banking establishments and specialized in maintaining an optimal continuity level and enhancing their competitiveness

4) Provide appropriate recommendations for taking measures to improve performance in Syrian banks

\section{Research Methodology}

This course is based on the analytical descriptive approach in addressing the problem of research, which is based on the examination and analysis focused on accurate information.

\section{Methods of Collecting Entities}

The source of data collection has been relied upon:

Preliminary sources: Methods of designing a questionnaire specific to the research variables, which have been developed and developed for the purpose of collecting field data by reference to previous research on the concept of Six Sigma. It has the following features:

Section I: The sections related to the independent compiler include the implementation of the Six Sigma (DMAIC) components.

The order of 1 to 12 , as well as paragraphs relating to the other independent spectral selection team.

Six Sigma optimization and ranking from 13 to 20 .

Section II: The paragraphs related to the dependent variable improve the performance of Syrian banks and rank from 21 to 29 . The level of response to each poverty was based on Likert scale as follows:

Strongly agree $=5, \mathrm{OK}=4$, neutral $=3$, not $\mathrm{OK}=2$, strongly disagree $=01$ 
To verify the apparent authenticity of the tool, the researcher presented the questionnaire to a group of specialists in the field of administrative research and in the light of their opinions, it was found that the terms of the scale are good and measure what is designed for it and bear a true apparent.

Secondary sources: Include scientific literature, studies and theoretical and field research in the previous books, periodicals and magazines Court.

\section{Community and Sample Search}

The research community consists of managers in the senior management, the middle, the branch, the heads of the departments and the employees in the sites with direct contact with the customers in the Syrian and private and traditional Syrian banks in Damascus. A simple random sample of 250 members was selected from this community.

A total of (250) questionnaires were distributed. Of the questionnaires distributed (228), of which (13) were completed, the answer was incomplete. The number of questionnaires valid for analysis reached (215) and 86\% of the questionnaires

It is considered a good ratio. The period of implementation of the field study was then analyzed from date $7 / 1 / 15$ to $15 / 9 / 15$. The following is a Table 1 showing the distribution of the research sample on Banks and its type in terms of nature of activity and ownership.

\section{Previous Studies:}

1) Salama (2014), entitled "A Proposed Accounting Framework for Measuring and Evaluating the Performance of Economic Institutions Using Balanced Scorecard Integration and Six Sigma"

2) The main objective of this research is to propose an accounting framework for measuring and evaluating the performance of economic entities by using the integration of the two balanced and balanced methods of performance card, based on scientific and methodological basis and verifying the applicability of this framework in the economic sector, Alone is sufficient in the light of modern environmental changes, as it does not pay attention to the long-term strategy of quality, the speed of meeting the needs of customers, as well as the success of learning programs and growth

3) Study (Abdullah, 2012) entitled "The extent of adherence to the Six Sigma approach in controlling the quality of internal auditing applied to banks operating in Gaza"

4) The aim of the study was to identify the adherence to the Six Sigma approach in controlling the quality of internal auditing by focusing on the following independent variables: Effective adherence to higher management, feedback, measurement, continuous improvement, operations and systems, human resources. And the dependent variable: Quality standards of internal auditing (professional competence, management of internal audit activities, field of work, planning and implementation of the internal audit process, delivery of results), the study found a statistically significant relationship between the commitment of banks operating in the Gaza Strip Internal Audit Quality

5) Quality (2011) entitled Improving Process Quality: Implementing Six Sigma Methodologies in Service Organizations

6) This course aims to provide a systematic framework for the implementation of 6 Sigma in service organizations in the countries concerned

7) In order to reduce errors in the processes and improve the quality of services provided. The researcher relied on descriptive analytical approach in addressing the problem of research, which was the statement of the most important operations in service organizations that should be focused on the extent of the possibility of reducing errors in service operations and the possibility of implementing six Sigma in service organizations, The conclusions indicated the importance of applying the six Sigma methodology in all service organizations and that the focus on input and output quality is not alone enough to provide good service, but also to focus on the quality of operations and reduce error rates

8) Karlsson (2010), "Six Sigma in Swedish Banks: A Practical Study of Six Sigma to Improve the Credit Process"

9) The course focused on improving the procedures of bank lending operations and developing their collection mechanism to reduce operational risks, turnover and increase customer satisfaction through the use of DMAIC, an important software in the implementation of Six Sigma through (problem identification, measurement, analysis, Censorship)

10) The results of the study showed that six Sigma can be used in Swedish banks, but the difficulties are in the availability of data and the competence of cadres in dealing with a wide range of data and information.

11) Study (Antony, 2006) »Six Sigma in Service Operations»)

12) The aim of this course is to demonstrate the power of Six Sigma as an approach to improving products, processes or quality of service in the service sector

13) As demonstrated by this school a set of techniques and tools used to obtain the development of the performance of the service process

14) Six Sigma's success factors include: Support and commitment of effective senior management, change of organizational culture, six Sigma projects aligned with business objectives, selection of team members, training policies, understanding of DMAIC methodology, linking Six Sigma to customer satisfaction and outcomes of financial cycles 
Table 1: Distribution of the research sample on banks and their type in terms of nature of activity and ownership

\begin{tabular}{lll}
\hline Number of distributed questionnaires & Bank type & Bank name \\
\hline 50 & Commercial General & Commercial Bank of Syria \\
50 & General Specialist & real estate Bank \\
25 & General Specialist & Agricultural Cooperative Bank \\
25 & General Specialist & Industrial Bank \\
25 & General savings & Popular Credit Bank \\
25 & General savings & Savings Bank \\
25 & Private Commercial & International Bank for Trade and Finance \\
25 & Commercial Islamic private & Syria International Islamic Bank \\
250 & Total sample size & \\
\hline
\end{tabular}

Source: Researcher Preparation

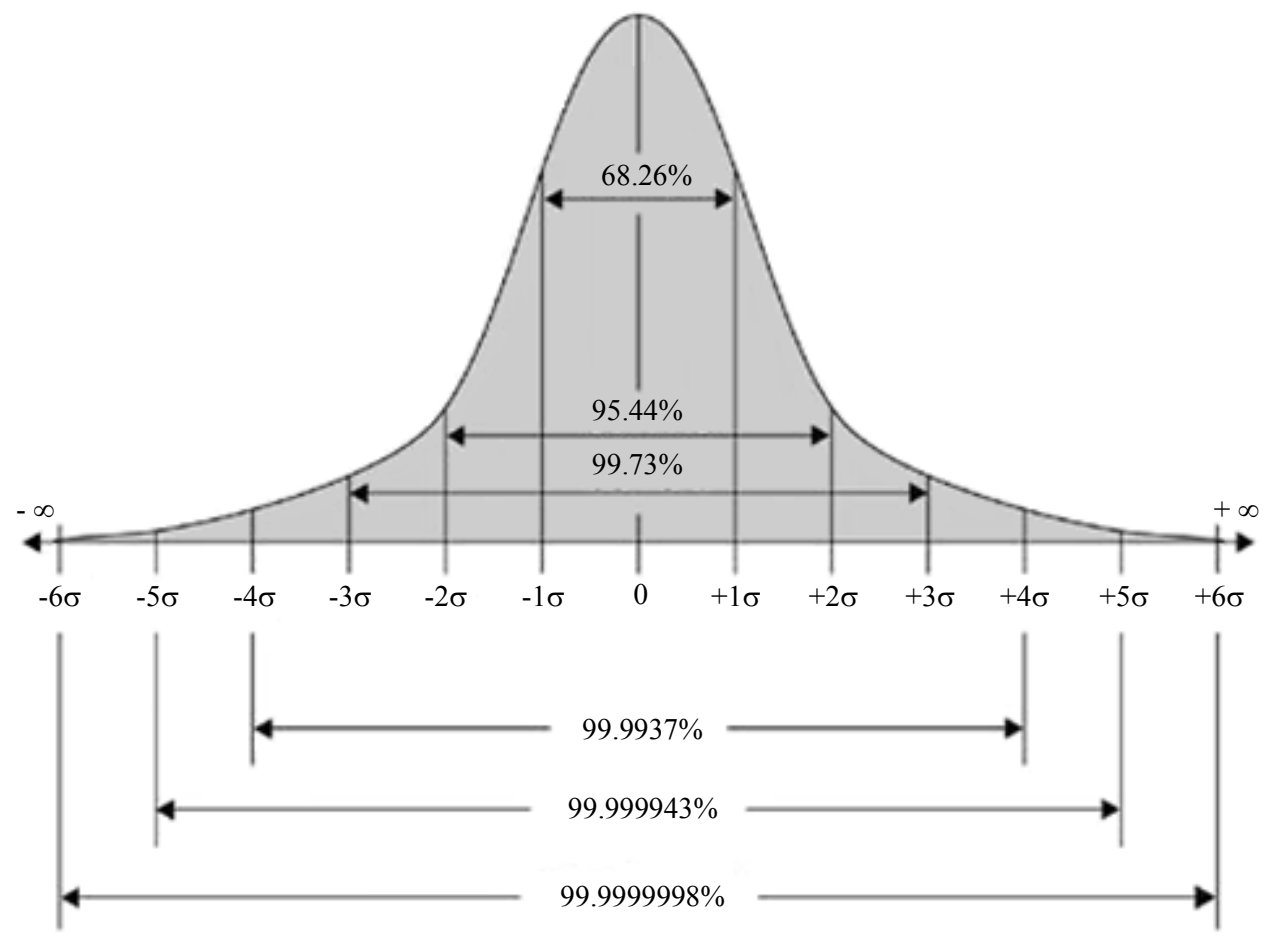

Fig. 1: Six Sigma levels under the natural curve (Pande and Holpp, 2002)

The space will be explained under the curve (acceptance area) and (rejection area) as follows:

- (Urdhwareshe, 2000, 1-5)

- The probability of $26.68 \%$ of the data under the curve ranges from $(1 \sigma) \pm$

- The probability of $46.95 \%$ of data under the curve

- $\quad$ ranges from $(2 \sigma) \pm$

- The probability of occurrence of $73.99 \%$ of the data under the curve ranges from $(3 \sigma) \pm$

And more precisely refers to reducing (errors) discrepancies to six deviations of the average value of the outputs of the process or the important opportunity, that is to say, in other words one error in 300000 chances.

This paper presents the various areas that enable the exploitation of six Sigma in service functions by providing some guidelines for the selection of six Sigma projects.

\section{Six Sigma Methodology}

\section{First: Six Sigma Concept}

The Six Sigma approach is one of the advanced management programs based on an advanced strategic dimension that contributes to building and sustaining sustained success by combining management and statistics in a coherent manner, flexibility and accuracy in the organization and continuous improvement of operations and meeting the changing needs of customers, markets and technology. Employees and shareholders.

Sigma is the 18th letter in the Greek alphabet and is used to measure dispersion in the statistic, where it expresses the mean of the sum of the squares of deviations of values from their arithmetic mean (Band and Hulp, 2005). 
According to the normal distribution of frequencies, the area of the natural distribution curve can be divided into a section in the mean of the arithmetic mean and the seismic. The area between the arithmetic mean and \pm 1 Sigma is approximately $68.27 \%$ of the total area or the total of the frequencies or cases, the space between the arithmetic mean and ( \pm 2 Sigma) is equal to $(95.45 \%)$ of the total area and thus the calculations are calculated to reach the calculation of the area between the mean and the mean ( \pm 6 Sigma) $(99,999,66 \%)$, which means that good cases, products or processes fall within this area, in other words, the opportunity to commit the error is (3.4) million.

Al-Qazzaz et al. (2009), defines Six Sigma as "a proven set of modern management techniques, analytical tools, project monitoring techniques and reporting, which combine to form improvements in problem solving and business performance."

Band et al. (2009) as a term that refers to a process that does not produce more than 3.4 million defects in opportunities and because this rate of defects is low, the term Six Sigma is associated with Zero Defects. Six Sigma can be represented in the following format:

\section{Second: The Emergence of Six Sigma}

The Six Sigma method began in the 1980s in Motorola. In 1983, quality engineer Bill Smith concluded that tests and tests did not detect all the faults of the product. Customers discovered these defects and those defects led to product failure. Since the failure rates of the process were higher than Becker, as indicated by the final product tests, Smith determined that the best way to solve the problem of defects is to improve processes to reduce.

The chances of having defects or disposing of them in the first place. Smith put the six Sigma standard almost perfect, at $99,999 \%$ - and put the name of the method (Pro, 2009).

\section{Third: The Six Sigma Main Principles}

Pande and Holpp (2002) referred to the basic principles of Six Sigma (Figure 1), which represent the ideas to be met as follows:

1) The real focus on customers where it must be realized that the main objective is the satisfaction of the customer or service beneficiaries

2) Dependence on facts and Figures when making any decision

3) To make improvements in the organization's core processes and mastery to build competitive advantage in target markets

4) Effective management based on proactive planning. Six Sigma works to transform management from making decisions as reactions to what happens to a planning department and taking precautions before problems arise

5) Unlimited cooperation, which means breaking the barriers between the different departments of the Organization and improving mechanisms of action at all levels of management

6) The pursuit of perfection with the ability to withstand failure, that is, if the organization wants to make six Sigma a target it must not resist change in the adoption and application of new ideas and methods and continue to seek to achieve more perfection in performance while accepting the thought of obstacles That you may encounter and work on their successful management

Fourth: Organizational Structure for the Six Sigma Project

Six Sigma employees are divided into four administrative levels (Quality, 2011):

1) Champion of the project, the main sponsor of the project, in addition to being a senior director of the organization, fights for the success of the project and considers himself the owner of every part of it and is able to work methods and methodology of Six Sigma

2) Master Black Belt: It helps diagnose problems and it is necessary to have a certificate of success in the relevant course. It requires extensive experience in project management and trains employees in the black and green belts campaign

3) Black Belt Holder: He leads the task forces to implement and evaluate the stages of the project, supervise the project's main activities and train the Green Belt campaign staff

4) Green Packages: They are members of the task forces. Their task is to collect, analyze and report on the level of achievement, most of them working part-time in addition to their usual work

\section{Results and Discussion}

\section{First: What is the Banking Performance}

To be familiar with banking performance and to have a comprehensive vision of it, to understand the concept of performance (Obada, 2008) know in general. "Performance in general is a continuous activity that reflects the organization's ability to exploit its capabilities according to certain criteria and standards that it sets according to its long-term goals."

Ibish (2010) described the performance as "a reflection of how the organization uses its financial and human resources and exploits them with images that make it capable of achieving its objectives." 
The goals associated with the business, customers and personal goals of all employees will be achieved through the integration of human capital with the Six Sigma equation to have the opportunity to further improve performance. Six Sigma is a new strategy for the company and a philosophy for continuous improvement and a path to relative perfection by reducing defects and errors. 3.4 per million chances.

\section{Second: Understanding the Critical Characteristics of Quality in Banking Services}

Service is a non-material physical activity or a heterogeneous and often atypical commodity, which is produced and consumed at the same time, require interaction and contact with the customer and cannot be resold, stored, transferred or exported elsewhere, but the service delivery system can be issued or transmitted Najem, Abboud, 2010.

In order for the service to meet the needs of customers according to their priorities, it is necessary to focus on the critical characteristics of quality. These characteristics are the main indicators of measurement in the service, including the following (Jones, 2004):

a. Time (service time - waiting time - turnaround time): In the services where the customer is involved in the process itself, time is an important consideration that plays a major role in service delivery. Here, these three types of time must be considered:

i. Service time: A time required for customer service

ii. Waiting time: The time the client is waiting within the organization until the work is completed

iii. Role time: the Total time that consists of service time and waiting time

b. Cost: Cost is sometimes a critical factor from a customer's point of view. It can be said that there is an overlap between time and cost. Sometimes the customer is willing to bear more of the cost in return for service in the shortest possible time

c. Employee behavior: In highly customer-driven services, employee behavior is a very important consideration. The employee's attitude toward a problem can be determined by the client if he / she wishes to continue to deal with this organization first

d. Information: The customer's access to accurate information in a timely manner is considered a very important aspect of his view and thus in determining his position on this organization

Six Quality Control is not only a way to measure and monitor error rates but extends to include a wide range of tools to improve performance and improve customer service.
The Six Sigma methodology requires encouraging creativity, making necessary operational and design improvements and reducing differences in customer demand and services (HUG, 2006).

The steps related to the implementation of the Six Sigma methodology can be summarized below. These steps are abbreviated to DMAIC to express the initials for each of these steps:

\section{Phase 1: Definition Define}

The first phase of this methodology involves identifying key processes that directly affect customer satisfaction in order to focus on them and study the possibilities of improvement such as reducing error rates, reducing transaction delivery time, etc. At this stage, the requirements and needs of clients are defined by listening to Voice of the customer (VOC), distributed questionnaires and analyzed their answers to identify the critical quality (CTQ) for customers, such as reliability, responsiveness, delivery time and the most important tools used to plan basic processes SIPOC is a shortcut to the following elements (Quality, 2011):

a. Supplier: Process suppliers who supply their inputs are identified

b. Inputs: Determine the input process of physical, human, informational and technological resources

c. Process: It is the procedure in converting input to output

d. Outputs: The services or information that results from operations

e. Customer: It is the party that receives the outputs of the current process and seeks to satisfy it and meet its needs and expectations

At this stage, the Project Charter documenting the Six Sigma project is also developed and provides all relevant information. The team project document consists of the following:

A) Describe the problem of work: Describe the current situation of the problem at work, such as the time of completion of the transaction takes forty minutes while customers demand that the transaction be completed within thirty minutes

B) Scope of work: A description of the starting point and endpoint of the process that identifies the activities to be designed or redesigned

C) Objectives: To determine the objectives to be achieved such as reducing the delivery time or completion of the transaction ten minutes during the next six months or increasing the sigma level from (3) to (5.5), for example

D) Limitations: To record any obstacles that may be encountered in the implementation process such as lack of resources or lack of adequate comptometers 
E) Project Plan: Develop a plan of action for the implementation of the improvement project, describing the activities to be implemented and naming the responsible for the implementation, in addition to the expected date of completion of the project

F) Selection of Team Members: Writing the names of the team members and what the belts are each of them. After preparing the team project document, the allocation of the resources necessary for the implementation and the timely provision of resources will be made

\section{Phase 2: Measurement Measure}

This stage is a very important step in implementing the Six Sigma approach because it requires the collection of data and information in order to understand the causes of the problem and to find the root causes of this problem and determine the best measures that can be used to determine the nature of the problem. At this stage, the members of the Six Sigma teams identify the internal processes that affect the expectations and requirements of the customers, which are defined by the critical characteristics of the quality. The defects associated with these internal processes are examined and the basic components of the system are studied:

- Outputs: The final product of the process (number of defects, level of customer satisfaction or profits)

- Process: Includes activities and tasks you perform to convert inputs into outputs

- Inputs are those that enter into the process and are converted to outputs. If inputs are poor, outputs are poor, input measurement helps to identify the problem

Defects per million opportunities are calculated by applying the following equation:

$$
\begin{aligned}
& \text { DPMO }=(\text { number of defects } * 1000000) / \\
& (\text { number of opportunities } * \text { number of units })
\end{aligned}
$$

The Table 2 shows the sigma and defect levels per million chances and the resulting rates for each Sigma level.

Example: There are 250 applications with 52 defects, four opportunities for defects: (length of waiting period for completion of transaction, lack of interest of customer, mistakes in filling out form, accounting errors). Six levels are calculated as follows: Number of defects/number of units (orders)*Number of opportunities $(=52 /(4 * 250)=$ $0.05252000={ }^{6} 10 * 0,052=$ DPMO.

$52000=610 * 0.052=$ DPMO in every million chances, which is almost equivalent to 3.1 sigma, i.e. the performance level is relatively weak and the bank needs further improvement.
Table 2: Sigma levels and defects per million chances and output rates for each Sigma level

\begin{tabular}{lll}
\hline The ratio & $\begin{array}{l}\text { The error per million } \\
\text { chances (DPMO) }\end{array}$ & Sigma level \\
\hline $99.99966 \%$ & 3.4 & 6 \\
$99.9767 \%$ & 233 & 5 \\
$99.3790 \%$ & 6210 & 4 \\
$93.32 \%$ & 66810 & 3 \\
$69.13 \%$ & 308700 & 2 \\
$30.23 \%$ & 697700 & 1 \\
\hline
\end{tabular}

Source: Band et al. (2009), p. 56

\section{Phase 3: Analysis}

At this stage, the team identifies the causes of the problem that require improvement and the team takes advantage of the information and data collected by analyzing it to identify the root causes that make the process not functioning properly. Six Sigma team explore the possible causes of the problem that may arise from different sources as follows (Band and Holb, 2005):

- Methods: The procedures, methods and techniques used to do the work

- Machines: It is the technology used such as computer, imaging equipment

- Materials: Data, instructions, numbers, facts, types of defects

- Measurements: There may be erroneous data produced by how measurement is measured

- Natural environment: Environmental elements such as weather, economic conditions affecting the performance of work

- Human Resources: Includes all individuals working in the Organization in various disciplines and administrative levels

The purpose of the analysis is to identify the causes of errors in the processes that were measured in the previous stage.

The Failure Mode and Effect Analysis (FMEA) is an important analytical tool used to determine how failure or errors affect Critical Quality (CTQ) standards. This tool allows you to anticipate, identify and then avoid potential errors Nabulsi, 2005).

\section{Phase 4: Improvement Improve}

Through this phase, the group of activities that contribute to improving the performance and upgrading of the facility is identified. The team uses scientific tools to find and identify possible solutions after determining the basic variables and their impact on the critical characteristics of the quality (Salayma, 2007).

\section{Phase 5: Control}

The objective of the control phase is to ensure that the changes that have been implemented have led to improved 
performance and are used at this stage Control Charts (Quality, 2011).

Requirements for the Success of Six Sigma Methodology in the Banking Sector

In order for banks with a leading position in the services sector to succeed in their efforts to implement the Six Sigma methodology, many of the most important requirements should be met (Escrig-Tean and Bon-Llusar, 2005):

a. Customer Focus: The main objective of implementing Six Sigma is to achieve customer requirements and deliver service without delay and without errors

b. Support and support senior management, train employees and introduce each of them in turn to apply the methodology

c. Employees committed and convinced six Sigma as a methodology for continuous improvement and keep in mind that the correct work must be done from the first time

d. The existence of an effective measurement system, in addition to the existence of an information system capable of delivering the information to the concerned party in a timely manner

e. Process analysis based on current and future customer needs. Based on this analysis, appropriate strategies will be developed to avoid operational errors

\section{Fifth: Analyzing the Questionnaire Data and Testing Hypothesis Validity}

The researcher used the Statistical Package for Social Sciences (SPSS) to analyze the incoming data. The indicators and the following tests were calculated:

- Alpha Cronbach coefficient to test the stability of the scale, the arithmetical averages and the standard deviations in order to judge the response of the research sample to the search variables, the difference Coefficient (C.V.) to show the dispersion of the data and its importance

- Test hypothesis validity using simple linear regression analysis to test the effect of each independent variable in the dependent variable

\section{Sixth: The Stability of the Study Tool}

The researcher tested the stability and internal consistency of each dimension individually and the scale as a whole on the methods of application on a sample of the sample of 50 (one) of the banking staff using the alpha coefficient Cronbach and the value is accepted statistically the coefficient of alpha Cronbach is $60 \%$ and more and the Table 3 demonstrates the stability test.

From Table 3 we find that all the dimensions gave high and good values ranged between [0.658 and 0.918]. The value of the Alpha Cronbach coefficient for all the expressions of stability was (0.914). This value expresses a very high degree of stability Reflects the consistency of respondents' answers, which in turn indicates the high ability of the study tool to measure what was designed for it.

\section{Seventh: Results Related to the Responses of the Sample}

Results related to the trends of the sample population of independent researcher variables:

\section{A) Application of Six Sigma (DMAIC) Components}

This variable shows the importance of applying the Six-Dimensional Dimensional Components (Selection Measurement - Analysis - Optimization -Supervision) in order to improve the performance of Syrian banks. The researcher calculated the arithmetical averages, standard deviations, percentages, differential coefficients and the significance of the order of the responses of the individual responses to the independent variable. The application of the Six Sigma (DMAIC) elements and the value (3) was used as an arithmetic mean, (4) the following results.

It is clear from Table 4 that the calculation averages ranged between [3.84-2.95]. In the first place, the statement of the Bank in dealing with any problem accurately identified in all its aspects was an average of 3.84. (3) In other words, there is a negative trend towards the bank's use of modern scientific methods to control the smooth operation and operations. This is due to the use of traditional and stereotyped control methods. From openness to international practices and the application of modern analytical tools. The difference coefficients (CV) were calculated to indicate the dispersion of the data, its importance and the degree of homogeneity. All the paragraphs were found to be valid, as all transactions were less than $(50 \%)$. Overall, we find that the individual sample of the research sample has a positive trend towards approving the implementation of the Six Sigma DMAIC model in order to improve the performance of the Syrian track. The mean value of the calculation is 3.36 and a good rate of $67.20 \%$.

\section{B) Selection of Team Six Sigma improvement}

This variable shows the importance of selecting the Six Sigma improvement teams to improve the performance of Syrian banks. Table 5 shows the arithmetical averages, standard deviations, percentages, differences coefficients and the significance of the order of the responses to individual responses to the independent variable. 


\section{Sigma}

From Table 5 we find that the values of the arithmetic averages ranged from [3.53 - 2.65]. The first was the ability of the employees of the bank to do additional work on their basic work, such as joining the improvement team on average.
My account (3.53), while you find that the words that there is no place for the women in the news of the improvement teams had an average arithmetic (2.80), which is less than the mean of the arithmetic mean (3), i.e., there is a negative trend in the vocabulary of the sample towards the absence of a place for the calculations in the selection of improvement teams.

Table 3: Stability coefficient (Alpha Cronbach method)

\begin{tabular}{llll}
\hline Alpha cronbach & Number of phrases & Axis & Axis number \\
\hline 0.841 & 12 & Apply six Sigma DMAIC model elements & 1 \\
0.658 & 8 & Six Sigma optimization team selected & 2 \\
0.918 & 9 & Improving the performance of Syrian banks & 3 \\
0.914 & 29 & All of the expressions are in question & 4 \\
\hline
\end{tabular}

Table 4: Trends in the research sample regarding the application of DMAIC model elements

\begin{tabular}{|c|c|c|c|c|c|c|}
\hline C.V. \% & $\begin{array}{l}\text { Importance of } \\
\text { order of the phrase }\end{array}$ & $\%$ & $\begin{array}{l}\text { Standard } \\
\text { deviation }\end{array}$ & Average & Application of six Sigma DMAIC model & $\mathrm{N}$ \\
\hline 22.69 & 1 & 76.80 & 0.871 & 3.84 & $\begin{array}{l}\text { The Bank usually deals with any problem by } \\
\text { carefully defining it in all its aspects }\end{array}$ & 1 \\
\hline 27.19 & 3 & 71.20 & 0.968 & 3.56 & $\begin{array}{l}\text { In dealing with a problem, the Bank usually distributes } \\
\text { appropriate roles to those responsible for resolving them }\end{array}$ & 2 \\
\hline 26.83 & 6 & 69.40 & 0.931 & 3.47 & $\begin{array}{l}\text { The Bank usually identifies and analyzes clients' } \\
\text { requirements and prioritizes them }\end{array}$ & 3 \\
\hline 27.75 & 7 & 66.00 & 0.916 & 3.30 & $\begin{array}{l}\text { The Bank usually devises a plan to collect data on the } \\
\text { problem to be resolved, including a specific time schedule }\end{array}$ & 4 \\
\hline 25.35 & 5 & 69.80 & 0.885 & 3.49 & $\begin{array}{l}\text { Data is usually collected in aggregate and then screened } \\
\text { for important information about the problem }\end{array}$ & 5 \\
\hline 26.062 & 4 & 70.60 & 0.920 & 3.53 & $\begin{array}{l}\text { The bank usually analyzes the data to get out the facts and } \\
\text { figures that represent important keys to the causes of the problem }\end{array}$ & 6 \\
\hline 27.13 & 2 & 72.60 & 0.985 & 3.63 & $\begin{array}{l}\text { Data analysis usually takes a long time due to complications, } \\
\text { old processes and previous administrative issues }\end{array}$ & 7 \\
\hline 29.93 & 8 & 65.20 & 0.976 & 3.26 & $\begin{array}{l}\text { The Bank usually provides good working conditions to help } \\
\text { employees to carry out their work under constant supervision }\end{array}$ & 8 \\
\hline 32.15 & 9 & 64.00 & 1.029 & 3.20 & $\begin{array}{l}\text { Managers and employees are trained in new } \\
\text { improved procedures }\end{array}$ & 9 \\
\hline 34 & 12 & 59.00 & 1.003 & 2.95 & $\begin{array}{l}\text { The Bank uses modern operational methods to } \\
\text { monitor workflow and operations }\end{array}$ & 10 \\
\hline 31.92 & 11 & 60.20 & 0.961 & 3.01 & $\begin{array}{l}\text { The Bank constantly reminds its employees of the results } \\
\text { of the optimization efforts that have been reached }\end{array}$ & 11 \\
\hline 31.95 & 10 & 62.40 & 0.997 & 3.12 & $\begin{array}{l}\text { The Bank makes great efforts to ensure that any gains } \\
\text { that the optimization team can achieve are maintained }\end{array}$ & 12 \\
\hline 17.88 & & 67.20 & $0.601 \%$ & 3.36 & Total & \\
\hline
\end{tabular}

Table 5: Trends of the sample of the research team regarding the selection of the improvement team Six Sigma

\begin{tabular}{|c|c|c|c|c|c|c|}
\hline C.V.\% & $\begin{array}{l}\text { The importance of } \\
\text { order of the phrase }\end{array}$ & Percentages & $\begin{array}{l}\text { Standard } \\
\text { deviation }\end{array}$ & Average & Application of six Sigma DMAIC model & $\mathrm{N}$ \\
\hline 26.66 & 2 & 67.80 & 0.904 & 3.39 & $\begin{array}{l}\text { Improvement teams and committees are usually } \\
\text { selected at the bank based on specific considerations } \\
\text { such as culture, activity, experience and education }\end{array}$ & 13 \\
\hline 34.96 & 7 & 56.00 & 0.979 & 2.80 & $\begin{array}{l}\text { There is no place for pros and cons to choose the } \\
\text { improvement teams }\end{array}$ & 14 \\
\hline 23.42 & 5 & 62.60 & 0.733 & 3.13 & $\begin{array}{l}\text { The Bank has achieved positive results through } \\
\text { previously selected teams }\end{array}$ & 15 \\
\hline 27.51 & 4 & 62.80 & 0.864 & 3.14 & $\begin{array}{l}\text { There are incentives and promotions for individuals } \\
\text { joining the optimization teams }\end{array}$ & 16 \\
\hline 25.16 & 3 & 65.80 & 0.828 & 3.29 & $\begin{array}{l}\text { There is some familiarity with some } \\
\text { basic and advanced statistical tools }\end{array}$ & 17 \\
\hline 24.96 & 6 & 60.40 & 0.754 & 3.02 & $\begin{array}{l}\text { There is a willingness to appoint experts and consultants in } \\
\text { the field of six Sigma within the staff working in the bank }\end{array}$ & 18 \\
\hline 33.66 & 8 & 53.00 & 0.892 & 2.65 & There is no need to have six Sigma teams within the bank & 19 \\
\hline 23.99 & 1 & 70.60 & 0.847 & 3.53 & $\begin{array}{l}\text { Bank employees have the ability to withstand the pressure } \\
\text { of work and do additional work on their core business, such } \\
\text { as joining Teams optimization using the Six Sigma method }\end{array}$ & 20 \\
\hline 15.70 & & 62.40 & 0.490 & 3.12 & Total & \\
\hline
\end{tabular}


The sample also confirmed its opposition to the idea of dispensing with the Six Sigma teams for improvement. There is no need to have six Sigma teams within the bank (2.65) and the last rank is that there is a negative trend towards the lack of improvement teams Six Sigma.

The difference coefficients (CV) were calculated to indicate the dispersion, importance and homogeneity of the data. All the sentences were found to be valid, with all transactions being less than 50\%. Overall, the research sample showed a positive trend towards the importance of selecting six sigma improvement teams in order to improve the performance. The mean of the mean (3.12) and the acceptable percentage reached (62.40\%).

Results related to the orientation of members of the research sample on improving the performance of Syrian banks:

The researcher calculated the arithmetical averages, the standard deviations and the difference coefficients. The importance of the order of the expressions for the respondents' responses to the dependent variable improved the performance of the Syrian banks. The value (3) was used as an arithmetic mean.

From Table 6 we find that the values of the arithmetic averages ranged between [3.63-3.26]. It was found that most of the sample members were inclined to accept the idea of the bank improving the performance of its operations and designing its services to meet the customers' desires. (3.63), while the expression that the improvement team members transferred what they learned to all those responsible for the process was improved, it ranked last with a mean (3.26). The CV coefficients were calculated to show the dispersion of data, its importance and the degree of homogeneity, All the paragraphs were found to be valid as all transactions were less than $(50 \%)$.

Overall, we find that the individual sample of the research sample has a positive attitude toward approval and readiness to improve the performance of Syrian banks. The average of the average (3.48) and the good rate reached $(69.60 \%)$.

\section{Eighth; Research Test}

The researcher used Simple Regression analysis to test hypotheses

To test the effect of each independent variable in the dependent variable, the following are the results of the hypothesis test:

The first hypothesis: (The application of elements of the Six Sigma model (DMAIC) does not affect the performance of banks (Syrian).

The Table 7 shows the results of a simple linear regression analysis to test the effect of applying Six Sigma (DMAIC) elements in improving the performance of Syrian banks.

Table 6: Trends of research sample members on improving the performance of Syrian banks

\begin{tabular}{|c|c|c|c|c|c|c|}
\hline C.V.\% & $\begin{array}{l}\text { The Importance of } \\
\text { order of the phrase }\end{array}$ & $\%$ & $\begin{array}{l}\text { Standard } \\
\text { deviation }\end{array}$ & Average & Application of six Sigma DMAIC model & $\begin{array}{l}\text { Number } \\
\text { question }\end{array}$ \\
\hline 22.60 & 2 & 2.207 & 0.816 & 3.61 & $\begin{array}{l}\text { The Bank supports continuous improvement } \\
\text { efforts in all its operations }\end{array}$ & 21 \\
\hline 23.27 & 5 & 70.40 & 0.819 & 3.52 & $\begin{array}{l}\text { The Bank continuously improves its performance } \\
\text { according to the operational perspective }\end{array}$ & 22 \\
\hline 25.075 & 7 & 66.60 & 0.835 & 3.33 & $\begin{array}{l}\text { There is speed in improving processes by addressing } \\
\text { problems that are precisely identified in their operations }\end{array}$ & 23 \\
\hline 22.70 & 3 & 71.00 & 0.806 & 3.55 & $\begin{array}{l}\text { Existing and existing improvement programs } \\
\text { in the Bank contribute to customer satisfaction }\end{array}$ & 24 \\
\hline 25.042 & 4 & 70.60 & 0.884 & 3.53 & $\begin{array}{l}\text { The Bank is concerned with activities and initiatives } \\
\text { that focus on customer satisfaction and are encouraged }\end{array}$ & 25 \\
\hline 21.95 & 1 & 72.60 & 0.797 & 3.63 & $\begin{array}{l}\text { The Bank seeks to improve the performance of its } \\
\text { operations and the design of its services to meet the } \\
\text { wishes of customers }\end{array}$ & 26 \\
\hline 24.55 & 6 & 69.40 & 0.852 & 3.47 & The bank documents all new enhanced procedures & 27 \\
\hline 25.64 & 9 & 65.20 & 0.836 & 3.26 & $\begin{array}{l}\text { Members of the optimization team communicate } \\
\text { what they have learned to all those responsible for } \\
\text { the process that has been improved }\end{array}$ & 28 \\
\hline 24.13 & 8 & 67.80 & 0.818 & 3.39 & $\begin{array}{l}\text { The Bank applies new enhanced procedures to address } \\
\text { similar problems that are subsequently exposed }\end{array}$ & 29 \\
\hline 18.22 & & 69.60 & 0.634 & 3.48 & & \\
\hline
\end{tabular}

Table 7: Results of regression analysis to test the impact of the implementation of DMAIC in improving the performance of Syrian banks

\begin{tabular}{|c|c|c|c|c|c|c|c|c|}
\hline \multirow[b]{2}{*}{ Sig } & \multirow[b]{2}{*}{$\mathrm{t}$} & \multicolumn{2}{|c|}{ Regression coefficients } & \multirow[b]{2}{*}{$\begin{array}{l}\text { Level of } \\
\text { significance (Sig) }\end{array}$} & \multirow[b]{2}{*}{$\mathrm{F}$} & \multirow[b]{2}{*}{$\mathrm{R}^{2}$} & \multirow[b]{2}{*}{$\begin{array}{l}\text { Correlation } \\
\mathrm{R}\end{array}$} & \multirow[b]{2}{*}{$\begin{array}{l}\text { Independent } \\
\text { variable }\end{array}$} \\
\hline & & $\begin{array}{l}---- \\
P\end{array}$ & Parameter & & & & & \\
\hline 0.000 & 6.218 & 10.518 & Fixed & 0000 & 156163 & 0.423 & $0650 * *$ & Apply six Sigma \\
\hline 0.000 & 12.497 & 0.515 & Impact degree $(\mathrm{Bi})$ & 0.000 & 100.100 & & & \\
\hline
\end{tabular}

The dependent variable: Improving the performance of Syrian banks 
Table 8: Results of regression analysis to test the impact of the Six Sigma optimization team in improving the performance of Syrian banks

\begin{tabular}{|c|c|c|c|c|c|c|c|c|}
\hline \multirow[b]{2}{*}{ Sig } & \multirow[b]{2}{*}{$\mathrm{t}$} & \multicolumn{2}{|c|}{ Regression coefficients } & \multirow[b]{2}{*}{$\begin{array}{l}\text { Level of } \\
\text { significance (Sig) }\end{array}$} & \multirow[b]{2}{*}{$\mathrm{F}$} & \multirow[b]{2}{*}{$\mathrm{R}^{2}$} & \multirow[b]{2}{*}{$\begin{array}{l}\text { Correlation } \\
\mathrm{R}\end{array}$} & \multirow[b]{2}{*}{$\begin{array}{c}\text { Independent } \\
\text { variable }\end{array}$} \\
\hline & & $\mathrm{P}$ & Parameter & & & & & \\
\hline 0.000 & 4.878 & 9.939 & $\begin{array}{l}\text { Fixed } \\
\text { regression (B0) }\end{array}$ & 0.000 & 112.906 & 0.346 & .589 & $\begin{array}{l}\text { Six Sigma Optimization } \\
\text { team selected }\end{array}$ \\
\hline 0.000 & 10.626 & .856 & Impact degree $(\mathrm{Bi})$ & & & & & \\
\hline
\end{tabular}

The dependent variable: Improving the performance of Syrian banks

It is clear from the values in Table 7 that the relationship between the variable application of the elements of the Six Sigma (DMAIC) model and the improvement of the performance of the Syrian banks is medium, positive and statistically significant. $\mathrm{R}^{2}$ explains $42 \%$ of the change in the ability to apply the Six Sigma (DMAIC) model to improve the performance of Syrian banks.

The slope of the effect (slope parameter) was 0.515 and the fixed value of 10.518 , both of which showed significant significance in the simple linear regression model by comparing the significant significance of the calculated value of $t$ for the model coefficients $(\mathrm{sig}=$ 0.00), which is less than the significance level of 0.05 . Alternative Hypothesis The application of Six Sigma model elements (DMAIC) affects the performance of Syrian banks.

The linear equation of the regression model illustrates the relationship between the application of six Sigma model elements (DMAIC) and improved performance of Syrian banks:

$$
Y=10.518+0.515 X 1
$$

Where:

$Y=$ The dependent variable - Improving the performance of Syrian banks

$X 1=$ Independent Variable- Apply Six Sigma DMAIC

The second hypothesis: (The selection of the Six Sigma team does not affect the performance of the Syrian banks).

The Table 8 shows the results of a simple linear regression analysis to test the impact of the Six Sigma optimization team in improving the performance of Syrian banks.

It is clear from the values in Table 8 that the relationship between the selection variable of the improvement team will be six and the performance of the Syrian banks will be medium, positive and statistically significant. The correlation coefficient $(\mathrm{R}=0.589)$ is at the level of (0.00) $(34.6 \%)$ of the change in the ability to choose the Six Sigma improvement teams to improve the performance of Syrian banks.

The coefficient of gravity is 0.856 and the fixed limit value is 9.939 , both of which reflect a significant significance in the simple linear regression model by comparing the significant significance of the calculated value of the coefficients of the model coefficients ( $\mathrm{Sig}=0.00)$, which is less than the significance level of 0.05 . Alternative Hypothesis The choice of six Sigma optimization teams affects the performance of Syrian banks.

The linear equation as the regression model shows the relationship between the choice of optimization teams and the improvement of the performance of Syrian banks:

$$
Y=9.939+0.856 \times 2
$$

Where:

$Y=$ The dependent variable - improving the performance of Syrian banks

$X 2=$ Independent variable - Six Sigma optimization team selection

\section{Conclusion}

From the results of the field study and the testing of research hypotheses, the following can be inferred:

a. The importance of studying and implementing Six Sigma methodology in all local sectors including industry and service sector

b. The research through its results reached a readiness of the Syrian banks to use the Six Sigma approach

c. There is significant statistical management between the implementation of the Six Sigma model (DMAIC) and improved performance of Syrian banks, where Syrian banks tend to identify and identify problems properly and then measure and analyze them, improve operations and provide conditions Good work under constant supervision

d. There is a significant statistical effect between the selection of the Six Sigma Team (improvement team) and the improvement of the performance of the Syrian banks. The research showed the importance of choosing the improvement teams in the correct and logical manner based on the experience and education and the ability to withstand the work pressure. Incentives and promotions for individuals joining the improvement teams 


\section{Recommendations}

In the light of previous conclusions, the following recommendations could be made:

1. The use of experts and consultants to apply the method Six Sigma in the banking sector of Syria

2. Open to the best practices in international experiences in the field of Six Sigma for the benefit of them

3. The Syrian banking system should adopt six Sigma as its quality management system

4. Expanding the training courses for Syrian banking cadres on six Sigma to understand the concept of methodology and how to apply it

5. Universities to train the methodology of Six Sigma in their curricula within the various disciplines of the Faculty of Economics and Administrative Sciences

6. To conduct future research in the application of Six Sigma methodology to the banking sector in other aspects as well as on the fields of service organizations such as hotels, airlines, insurance and others

\section{Ethics}

The author has no conflict of interest to report.

\section{References}

Abdullah, H., 2012. Compliance with the Six Sigma approach to the quality of internal audit applied to banks operating in Gaza. MSc Thesis, Faculty of Commerce, Islamic University, Gaza.

Al-Qazzaz, I.I., R.H. Al-Hadithi and A.A.M. Corel, 2009. Six Sigma and other modern methods in TQM. Dar Al Masirah for Publishing and Distribution, Amman.

Antony, J., 2006. Six sigma for service processes. Bus. Process Manage. J., 2: 234-248. DOI: $10.1108 / 14637150610657558$

Band, H. and L. Holb, 2005. Six Sigma vision advanced in total quality management. Translation of Osama Ahmed Musm, Dar Al-Marikh, Riyadh.

Band, P.S. R.B. Newman and R.R. Cavanagh, 2009. Manig SIGMA 6 how general electric, Motorola and other major companies have developed their performance. Jarir Bookstore, Riyadh.
Escrig-Tena, A.B. and J.C. Bon-Llusar, 2005. A model for evaluating organizational competencies: An application in the context of a quality management initiative. Decision Sci., 36: 221-258. DOI: $10.1111 / \mathrm{j} .1540-5414.2005 .00072 . x$

Hug, Z., 2006. Six Sigma implementation through Competency Based Perspectiven (CBP). J. Change Manage., 6: 277-289. DOI: $10.1080 / 14697010600941825$

Ibish, R.B.Z., 2010. The role of applying TQM in the development of banking management performance. MSc Thesis, Faculty of Economics, University of Aleppo.

Jones, M.H., 2004. Six sigma: At a bank. ASQ Six Sigma Magazine, 3: 13-17.

Karlsson, J.O., 2010. Six Sigma in swidish banking. MSc Thesis, Lulea University of Technology, Stockholm, Swedish.

Nabulsi, M., 2005. The secrets of hexagonal diffraction. Dar Wael Publishing, Amman.

Obada, I.A.H., 2008. Performance indicators in Islamic Banks. Dar Al Nafais, Amman.

Pande, P.S. and L. Holpp, 2002. What is Six Sigma. 1st Edn., Mc Graw-Hill, New York, ISBN-10: 0071381856, pp: 87.

Pro, G., 2009. Sigma 6 for Managers 24 lessons for the Values and Application of Six Sigma Principles in any Institution. 2nd Edn., Jarir Bookstore, Riyadh.

Quality, M.A., 2011. Improving process quality: Implementing 6 Sigma in service organizations, quality and excellence in business organizations. The Arab Society Library for Publishing and Distribution, Part One, Amman.

Salama, H.A.A., 2014. A proposed accounting framework for measuring and evaluating the performance of economic entities using integration between the two balanced performance card styles and six Sigma. Unpublished doctoral dissertation, Benia University, Egypt.

Salayma, N.H., 2007. Six Sigma can be used to improve health performance at the Arab Medical Center (Amman, Jordan), MSc Thesis, College of Administrative and Financial Studies, Amman Arab University for Studies High, Amman. 